\title{
Renal Tubular Reabsorption of Iodide as Compared with Chloride*
}

\author{
Mackenzie Walser $†$ and W. Joseph Rahill $\$$ \\ (From the Department of Pharmacology and Experimental Therapeutics and the Department \\ of Medicine, Johns Hopkins University School of Medicine, Baltimore, Md.)
}

The hypothesis examined in this study is that iodide reabsorption is chiefly passive, occurring in the same portions of the nephron as the reabsorption of chloride and other small monovalent anions, with the ratio of the permeability of the tubule to iodide to its permeability to chloride a constant. If this were true, iodide clearance and chloride clearance would be interrelated in a uniform manner, and it should be possible to predict iodide clearance from chloride clearance. Furthermore, the relationship between the two clearances should be independent of the plasma level of either halide.

To test this hypothesis, observations have been made of simultaneous iodide and chloride clearances, varied over a wide range in individual experiments. Many different agents, singly and in combination, were employed to induce variations in halide clearance and plasma halide levels.

In analyzing the results, it is desirable to use a simple mathematical model of the relationship between the two clearances and to ascertain whether this relationship is altered by the experimental manipulations. Such a model should have some theoretical support and should also give a good fit to the data. For passively reabsorbed solutes, a

\footnotetext{
* Submitted for publication February 1, 1965; accepted April 28, 1965.

Supported by U. S. Public Health Service grant A-2306. Preliminary accounts of this work have appeared $(1,2)$. The computations in this work were performed in the Computing Center of the Johns Hopkins Medical Institutions, which is supported by U. S. Public Health Service grant FR-00004.

† Supported by the U. S. Public Health Service Research Career Program (GM-K3-2583). Address requests for reprints to Dr. Mackenzie Walser, Johns Hopkins University School of Medicine, Department of Pharmacology and Experimental Therapeutics, 725 North Wolfe Street, Baltimore, Md. 21205.

$\ddagger$ Present address: Department of Pediatrics, Columbia College of Physicians \& Surgeons, New York, N. Y. Supported by U. S. Public Health Service training grant HTS-5159.
}

major determinant of clearance is the rate of water reabsorption, because one of the driving forces for solute reabsorption is the rise in tubular concentration produced by water removal. Changes in outflow of water are therefore accompanied by like changes in the outflow of such solutes. In mathematical models of uniform segments, the excreted/ filtered fractions of two such solutes are nearly constant powers of one another when the rate of water reabsorption changes (3). This is true whether water reabsorption is linear or exponential with length.

Besides variations in water reabsorption, variations in inflow and changes in the transtubular electrical potential difference can presumably cause changes in the clearances of passively reabsorbed ions. It is not certain whether the power function relationship would be followed under these circumstances. However, the effects of changes in water reabsorption on clearances are probably more important.

Therefore the mathematical model used to analyze the results was simply, excreted/filtered $\mathrm{I}^{-}=$ (excreted/filtered $\left.\mathrm{Cl}^{-}\right)^{\mathrm{k}}$, where $\mathrm{k}$ is a constant. By fitting the results to a constant value for $\mathrm{k}$ in each experiment, rather than a constant value in each dog or a single value for all dogs, it becomes possible to allow for variation in this quantity from subject to subject and also from experiment to experiment in a single subject. Only when this was done could a reasonable fit of the data to this model be obtained.

\section{Methods}

Twenty-nine experiments were performed on $13 \mathrm{fe}-$ male mongrel dogs anesthetized with sodium pentobarbi$\mathrm{tal}, 30 \mathrm{mg}$ per $\mathrm{kg}$. Before half of the experiments, salt depletion was induced by one or more of the following measures: feeding a low sodium diet (Lonalac) for several days, giving chlorothiazide $(0.5 \mathrm{~g}) 1$ or 2 days beforehand, or infusing an isosmotic solution containing mannitol and sodium sulfate at 1 to $2 \mathrm{ml}$ per minute per 
$\mathrm{kg}$ for several hours. At least 1 week elapsed between successive experiments in a single dog. Residual plasma or urine radioactivity at the start of the experiments was negligible. Priming doses and a constant infusion of inulin and radioactive iodide ( $\mathrm{I}^{181}$, carrier-free, kept in sodium bisulfite solution until use) were given in each experiment. The technique of collection of samples and the analytical methods are described elsewhere $(4,5)$. The composition of the infusions is shown in Table I. Carrier-free radioactive bromide was also given in 12 of these experiments. $\mathrm{I}^{131}$ was determined in these instances after $\mathrm{Br}^{82}$ had decayed to negligible levels.
Filtered iodide was calculated as plasma $\mathrm{I}^{131}$ times inulin clearance. In five plasma samples from these experiments subjected to ultrafiltration (6), protein-binding of iodide was negligible, in confirmation of previous reports (7-9). The results were analyzed statistically as follows.

It was assumed that the ratio $\log$ (excreted/filtered I)/ $\log ($ excreted/filtered $\mathrm{Cl})$ has a characteristic value in each experiment, independent of the excreted/filtered fractions themselves. Experimental variables such as infusion rates, plasma composition, urine flow, and filtration rate were considered to affect this ratio as multiple simul-

TABLE I

Plan of experiments*

\begin{tabular}{|c|c|c|c|c|c|}
\hline Dog & Wt. & $\begin{array}{l}\text { Exp. } \\
\text { no. }\end{array}$ & Diet & $\begin{array}{c}\text { Sustaining } \\
\text { infusiont }\end{array}$ & Additional infusions \\
\hline $6 C$ & $\begin{array}{l}\mathrm{kg} \\
9.8 \\
9.6 \\
9.6\end{array}$ & $\begin{array}{l}1 \\
2 \\
3\end{array}$ & $\begin{array}{l}\text { Low salt } \\
\text { Regular } \\
\text { Low salt }\end{array}$ & $\begin{array}{l}\mathrm{ACPN} \\
\mathrm{B} \\
\mathrm{B}\end{array}$ & $\begin{array}{l}\bar{o}, \mathrm{E}+\mathrm{F} \\
\bar{o}, \mathrm{E}, \mathrm{G} \\
\bar{o}, \mathrm{H}, \mathrm{I}\end{array}$ \\
\hline $6 \mathrm{E}$ & 15.6 & 1 & Regular & $\mathrm{ACPN}$ & $E+F, F$ \\
\hline $6 \mathrm{~F}$ & $\begin{array}{l}12.0 \\
10.4 \\
11.4 \\
12.6 \\
11.8 \\
13.5\end{array}$ & $\begin{array}{l}1 \\
2 \\
3 \\
4 \\
5 \\
6\end{array}$ & $\begin{array}{l}\text { Regular } \\
\text { Low salt } \\
\text { Regular } \\
\text { Low salt } \\
\text { Low salt } \\
\text { Regular }\end{array}$ & $\begin{array}{l}\text { APN } \\
\text { ACN } \\
\text { B } \\
\text { B } \\
\text { B } \\
\text { A }\end{array}$ & $\begin{array}{l}\mathrm{K}, \mathrm{F} \\
\bar{o}, \mathrm{~F}, \bar{o} \\
\bar{o}, \mathrm{E}, \mathrm{G} \\
\bar{o}, \mathrm{G}+\mathrm{F} \\
(\mathrm{F}), \mathrm{E}+\mathrm{F}, \bar{o} \\
\bar{o}, \mathrm{~J}\end{array}$ \\
\hline $6 \mathrm{G}$ & $\begin{array}{l}13.0 \\
12.0 \\
14.0 \\
14.5\end{array}$ & $\begin{array}{l}1 \\
2 \\
3 \\
4\end{array}$ & $\begin{array}{l}\text { Regular } \\
\text { Low salt } \\
\text { Regular } \\
\text { Low salt }\end{array}$ & $\begin{array}{l}\text { ACPN } \\
\text { A } \\
\text { A } \\
\text { B }\end{array}$ & $\begin{array}{l}(\mathrm{K}), \mathrm{F} \\
\bar{o}, \mathrm{E}+\mathrm{F} \\
\bar{o}, \mathrm{~F}, \mathrm{~J} \\
\bar{o}, \mathrm{I}\end{array}$ \\
\hline $6 \mathrm{H}$ & $\begin{array}{l}16.0 \\
19.8\end{array}$ & $\begin{array}{l}1 \\
2\end{array}$ & $\begin{array}{l}\text { Low salt } \\
\text { Regular }\end{array}$ & $\underset{A}{A C P N}$ & $\begin{array}{l}\bar{o}, \mathrm{E}+\mathrm{F} \\
\bar{o}, \mathrm{~F}, \mathrm{~J}\end{array}$ \\
\hline 61 & 6.6 & 1 & Low salt & $\mathrm{ACPN}$ & $\bar{o}, \mathrm{E}+\mathrm{F}$ \\
\hline $6 \mathrm{~J}$ & 8.0 & 1 & Low salt & ACPN & $\bar{o}, \mathrm{E}+\mathrm{F}$ \\
\hline $6 \mathrm{~K}$ & $\begin{array}{l}11.5 \\
12.6 \\
11.4 \\
12.2 \\
12.0 \\
12.0\end{array}$ & $\begin{array}{l}1 \\
2 \\
3 \\
4 \\
5 \\
6\end{array}$ & $\begin{array}{l}\text { Regular } \\
\text { Regular } \\
\text { Low salt } \\
\text { Low salt } \\
\text { Regular } \\
\text { Regular }\end{array}$ & $\begin{array}{l}\text { B } \\
\text { B } \\
\text { B } \\
\text { A } \\
\text { A } \\
\text { A }\end{array}$ & $\begin{array}{l}\bar{o}, \mathrm{~F} \\
\bar{o}, \mathrm{E}+\mathrm{F} \\
(\mathrm{F}), \mathrm{E}+\mathrm{F}, \mathrm{E} \\
(\mathrm{F}+\mathrm{G}), \bar{o}, \mathrm{E} \\
\mathrm{J} \\
\bar{o}, \mathrm{E}+\mathrm{F}, \mathrm{I}\end{array}$ \\
\hline $6 \mathrm{~L}$ & 13.4 & 1 & Low salt & A & $(\mathrm{G}), \bar{o}, \mathrm{E}$ \\
\hline $6 \mathrm{P}$ & 6.8 & 1 & Low salt & A, J & $\bar{o}, \mathrm{C}, \mathrm{E}$ \\
\hline $6 \mathrm{R}$ & 8.0 & 1 & Low salt & $\mathrm{A}, \mathrm{J}$ & $(\mathrm{F}+\mathrm{G}), \bar{o}, \mathrm{C}, \mathrm{E}$ \\
\hline $6 \mathrm{~W}$ & 14.0 & 1 & Low salt & A & $(\mathrm{L}), \mathrm{F}+\mathrm{M}$ \\
\hline $6 \mathrm{Y}$ & 13.4 & 1 & Regular & A & $(\mathrm{L}), \bar{o}, \mathrm{E}, \mathrm{H}$ \\
\hline
\end{tabular}

* Symbols: $\bar{o}$, none; A, glucose 0.3 mole per L; B, glucose 1.2 moles per L; C, NaSCN 0.001 to 0.005 mole per L; $\mathrm{P}, \mathrm{NaClO}_{4} 0.001$ to 0.005 mole per $\mathrm{L} ; \mathrm{N}, \mathrm{NaNO}_{3} 0.001$ to 0.005 mole per $\mathrm{L} ; \mathrm{D}, \mathrm{NaBr} 0.16$ mole per $\mathrm{L} ; \mathrm{E}, \mathrm{NaCl} 0.16$ mole per $\mathrm{L} ; \mathrm{F}$, mannitol 0.3 mole per L; G, $\mathrm{Na}_{2} \mathrm{SO}_{4} 0.1$ to 0.12 mole per $\mathrm{L} ; \mathrm{H}, \mathrm{NaHCO}_{3} 0.16$ mole per $\mathrm{L} ; \mathrm{I}, \mathrm{HCl} 0.1$ $\mathrm{N}, \mathrm{NaCl} 0.1$ mole per $\mathrm{L} ; \mathrm{J}$, NaI 0.16 mole per $\mathrm{L} ; \mathrm{K}, \mathrm{NaCl} 0.3$ mole per L, mannitol 0.45 mole per $\mathrm{L}, \mathrm{KCl} 0.005$ mole per L; $\mathrm{L},\left(\mathrm{NH}_{4}\right)_{2} \mathrm{SO}_{4}$ or $\mathrm{NH}_{4} \mathrm{Cl}$ on previous day; $\mathrm{M}, \mathrm{Na}_{2} \mathrm{SO}_{4} 0.1$ mole per $\mathrm{L}, \mathrm{H}_{2} \mathrm{SO}_{4} 0.04 \mathrm{~N}$. Infusions in parentheses given before start of experiments.

$\dagger$ All animals received inulin and $I^{131}$ by priming injection and sustaining infusion, except experiments $6 \mathrm{~F} 6$ and $6 \mathrm{~K} 5$, in which no $\mathrm{I}^{131}$ prime was given. Dogs receiving infusions $\mathrm{B}, \mathrm{C}, \mathrm{P}$, and $\mathrm{N}$ also received priming injections of these solutes. 
TABLE II

Iodide and chloride clearance following salt depletion and during repletion*

\begin{tabular}{|c|c|c|c|c|c|c|c|}
\hline \multirow[b]{2}{*}{ Time } & \multicolumn{2}{|c|}{ Plasma } & \multicolumn{2}{|c|}{ Urine } & \multicolumn{2}{|c|}{ Excreted/filtered } & \multirow[b]{2}{*}{ kł } \\
\hline & $\mathrm{Cl}$ & $I^{181}$ & Flow & GFRt & $\mathrm{Cl}$ & $\mathbf{I}^{181}$ & \\
\hline $\min$ & mmoles $/ L$ & $c p m$ & \multicolumn{2}{|c|}{$m l / m i n$} & & & \\
\hline 0 & \multicolumn{7}{|c|}{$\begin{array}{l}\text { Inulin } 0.8 \mathrm{~g} \text {, I131 } 10 \mu \mathrm{c} \text { iv } \\
\text { Start inulin } 300 \mathrm{mg} \text { per } 100 \mathrm{ml} \text {, glucose } 0.3 \text { mole per L, I }{ }^{131} 20 \mu \mathrm{c} \text { per L, at } 2.1 \mathrm{ml} \text { per minute }\end{array}$} \\
\hline $\begin{array}{l}145-155 \\
155-165\end{array}$ & $\begin{array}{l}100 \\
101\end{array}$ & $\begin{array}{l}755 \\
741\end{array}$ & $\begin{array}{l}0.20 \\
0.18\end{array}$ & $\begin{array}{l}50 \\
50\end{array}$ & $\begin{array}{l}0.00042 \\
0.00029\end{array}$ & $\begin{array}{l}0.0073 \\
0.0056\end{array}$ & $\begin{array}{l}(0.63) \\
(0.64)\end{array}$ \\
\hline 197 & \multicolumn{7}{|c|}{ Start additional infusion of saline 0.16 mole per $\mathrm{L}$, mannitol 0.15 mole per $\mathrm{L}$ at $3 \mathrm{ml}$ per minute } \\
\hline $\begin{array}{l}200-210 \\
240-250\end{array}$ & $\begin{array}{l}100 \\
102\end{array}$ & $\begin{array}{r}734 \\
1,135\end{array}$ & $\begin{array}{l}0.52 \\
0.72\end{array}$ & 54 & $\begin{array}{l}0.00090 \\
0.0051\end{array}$ & $\begin{array}{l}0.0346 \\
0.112\end{array}$ & $\begin{array}{l}0.48 \\
0.42\end{array}$ \\
\hline 270 & \multicolumn{7}{|c|}{ Increase additional infusion to $6 \mathrm{ml}$ per minute } \\
\hline $285-295$ & 100 & 845 & 0.95 & 50 & 0.0088 & 0.162 & 0.38 \\
\hline 295 & \multicolumn{7}{|c|}{ Change additional infusion to saline 0.3 mole per $\mathrm{L}$, mannitol 0.15 mole per $\mathrm{L}$} \\
\hline $\begin{array}{l}300-310 \\
330-340\end{array}$ & $\begin{array}{l}102 \\
115\end{array}$ & $\begin{array}{l}803 \\
706\end{array}$ & $\begin{array}{l}1.41 \\
2.70\end{array}$ & $\begin{array}{l}51 \\
65\end{array}$ & $\begin{array}{l}0.0155 \\
0.0519\end{array}$ & $\begin{array}{l}0.193 \\
0.298\end{array}$ & $\begin{array}{l}0.40 \\
0.41\end{array}$ \\
\hline
\end{tabular}

${ }^{*}$ Dog 6G, $12.0 \mathrm{~kg}$, low salt diet.

$\dagger \mathrm{GFR}=$ glomerular filtration rate.

$\ddagger k=\log ($ excreted/filtered I)/log (excreted/filtered $\mathrm{Cl}$ ). Values in parentheses excluded from the statistical analysis because of low clearances.

taneous regressors. Scores were assigned for the values of each regressor in each period, based upon actual measurement or, in the case of solutes infused but not analyzed, based upon the number of periods infused. In the case of these solutes, two regressors were introduced. For the first, a rising score was assigned based upon the infusion rate and the number of periods during which the infusion was given. For the second regressor, a score was assigned after the infusion was stopped for the waning effect of the infusion. For example, if sulfate was given moderately rapidly for four periods, and then stopped while five more periods were obtained, the ongoing scores (first regressor) for sulfate were assigned values of $1,2,3,4,4,4,4,4,4$, whereas the waning effect (second regressor) of sulfate was scored as $0,0,0,0$, $1,2,3,4,4$ in the nine periods, respectively. Thus, if the ongoing effect of sulfate (per period infused) on the discrimination factor were +0.01 , and if the waning effect were of the same magnitude but opposite in sign, the net effect in each period would be $+0.01,0.02,0.03,0.04$, $0.03,0.02,0.01,0.00,0.00$. On the other hand, if the effect of sulfate waxed more rapidly than it waned, some effect would persist throughout the experiments.

Although the procedure followed for assigning scores to the individual regressors suffers from the lack of a rigorous basis for infusions such as sulfate, it clearly represents an improvement over simply separating periods into those with and those without a given infusion. There are many experimental variables that cannot be introduced in a square wave fashion into the whole animal. Furthermore, if the magnitude of a regressor can be varied within studies as well as between studies, a more reliable estimate of its effect can (in theory) be obtained.

In analyzing this sort of experimental situation in which regressors vary both between and within studies, it is difficult to obtain a reliable estimate of the study-tostudy variance component. This is needed in making a weighted combination of between- and within-study regressions. The calculations involved are too extensive to be practicable by ordinary means, but are readily performed by high speed computer. A method for this analysis using a computer program was developed and was used in this work (10).

Periods in which excreted/filtered chloride was less than 0.002 were considered separately and were not subjected to statistical analysis, because of the possibility of a small amount of contamination with blood leading to spurious estimates of iodide-chloride discrimination in these samples. Obviously such contamination could only increase the clearance ratios of both ions, so that the true values could have been lower, but not higher, than the measured values. Groups of collection periods in which glomerular filtration rate was less than $2 \mathrm{ml}$ per minute per $\mathrm{kg}$ were discarded, as were any grossly bloody urine samples. The infusions were classified in two groups: those intended only to augment salt excretion or urine flow, including mannitol, hypertonic glucose, and saline; and those with possible effect upon iodide-chloride discrimination, including acid, bicarbonate, and foreign anions. The multiple regression analysis included these latter agents and also urine flow, filtration rate, and plasma chloride concentration.

\section{Results}

The relationship between iodide and chloride clearance. Representative experiments are shown in Tables II to IV. In the experiment shown in Table II, iodide and chloride clearances were both very low in the control periods following the feed- 
ing of a low salt diet. Infusion of saline and mannitol led to a 100 -fold increase in chloride clearance and a 40 -fold increase in iodide clearance. The calculated discrimination factor, $\mathrm{k}$, was initially 0.63 , but remained between 0.38 and 0.42 in the last four periods despite a tenfold increase in chloride clearance. Similar parallelism between chloride and iodide clearance during loading with saline and mannitol was seen in 19 experiments.

Changes in acid-base balance were induced in five experiments, one of which is shown in Table III. In this dog, acidosis was induced before the experiment by giving a large dose of ammonium chloride orally. Halide clearances were at first increased by means of infusing saline without correcting the acidosis; the discrimination factor $\mathrm{k}$ varied from 0.42 to 0.47 . The acidosis was then corrected with sodium bicarbonate; $\mathrm{k}$ varied from 0.35 to 0.41 during these periods. Although these results might suggest a change in the iodide-chloride discrimination factor with acidosis, statistical analysis of the data from all five experiments failed to support this impression, as shown below.

Stable iodide was infused in four experiments, and its clearance was determined as well as that of radioiodide. One of these is shown in Table IV. Except for the first two periods, in which chlo- ride clearance ratio was less than 0.002 , the discrimination factor $\mathrm{k}$ remained nearly constant despite a progressive elevation of plasma iodide to 19 mmoles per L. Stable iodide clearances were similar to radioiodide clearances. Some of the disparities are probably attributable to the rapidly changing plasma level of stable iodide. In the other three experiments, less drastic changes in plasma iodide were induced, and the two clearances were more nearly equal. A comparison of the two clearances in all four studies is shown in Figure 1. No consistent difference was detected.

Other agents studied in various combinations included sulfate, bromide, thiocyanate, perchlorate, and nitrate.

The average discrimination factor in the $29 \mathrm{ex}$ periments varied from 0.28 to 0.66 , being between 0.34 and 0.50 in all but three. Because of this considerable variation from study to study, a plot of all the data fails to indicate the constancy of $k$ in individual experiments. Although the fit of the data to a power function could be illustrated by graphs of each individual experiment including these last three, for the sake of simplicity the results in the 26 other experiments are shown together in Figures 2 and 3, on linear and logarithmic coordinates, respectively. These graphs show

TABLE III

Iodide and chloride clearance during acidosis and after correction*

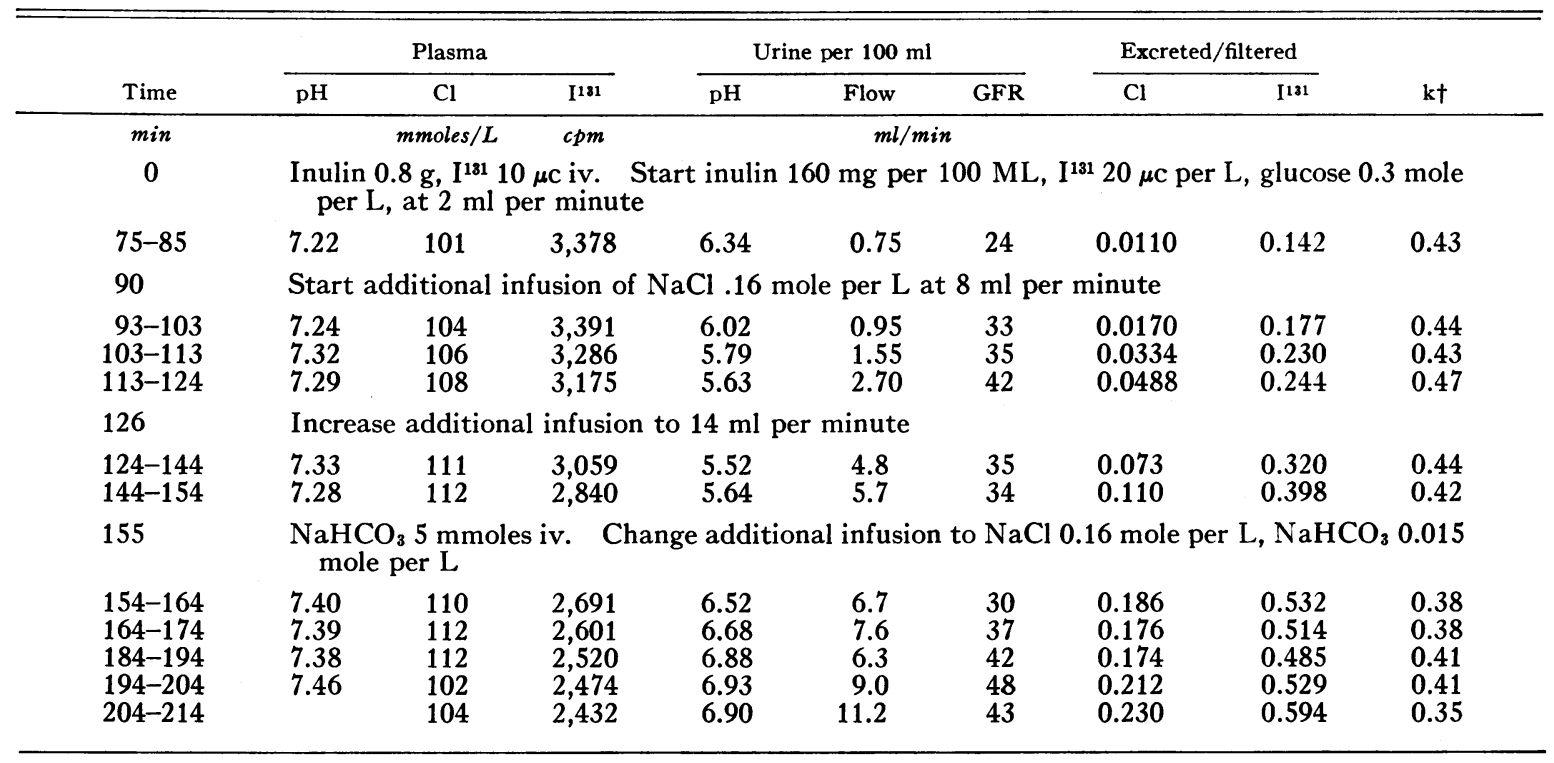

* Dog $6 \mathrm{Y}, 13.4 \mathrm{~kg}$, regular diet; $\mathrm{NH}_{4} \mathrm{Cl}, 10 \mathrm{mEq}$ per $\mathrm{kg}$ by mouth on the previous day.

$\dagger \mathbf{k}=\log ($ excreted/filtered I)/log (excreted/filtered $\mathrm{Cl})$. 
TABLE IV

Iodide and chloride clearance during iodide infusion*

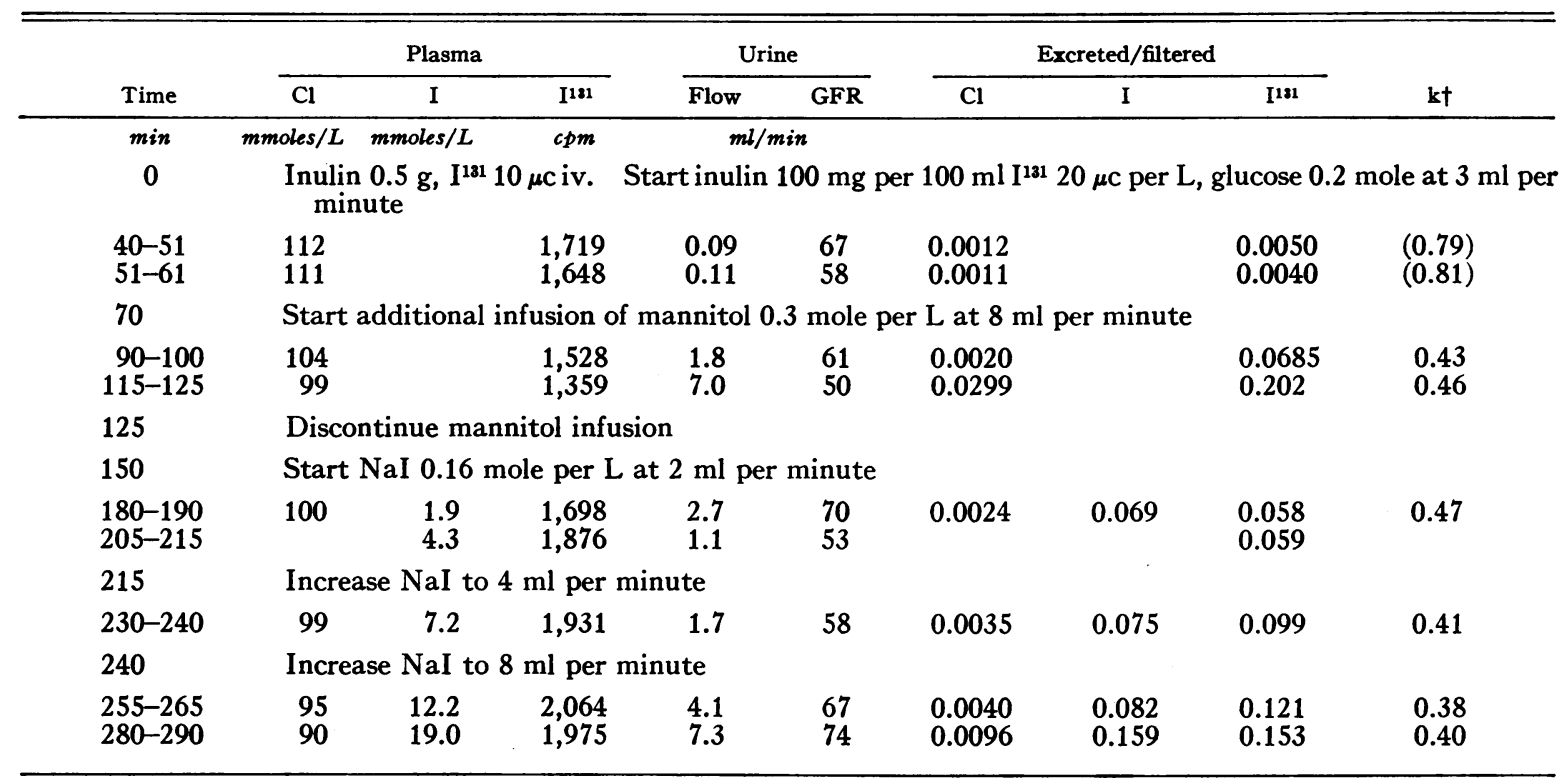

* Dog 6G, $14.2 \mathrm{~kg}$, regular diet.

$\dagger \mathrm{k}=\log \left(\right.$ excreted/filtered $\left.\mathrm{I}^{131}\right) / \log$ (excreted/filtered $\mathrm{Cl}$ ). Values in parentheses excluded from the statistical analysis because of low clearances.

that the two clearances are highly correlated, and that the relationship is curvilinear on linear coordinates but linear on logarithmic coordinates. Furthermore, there is no intercept at the upper right-hand corner of Figure 3, where $\log$ (excreted/filtered) equals zero for both ions. These graphs and the values of $k$ shown in Tables II to IV indicate that the mathematical model employed gives a reasonably good fit to the experimental data.

The relationship between iodide and chloride clearance at extremely low values of chloride clear-

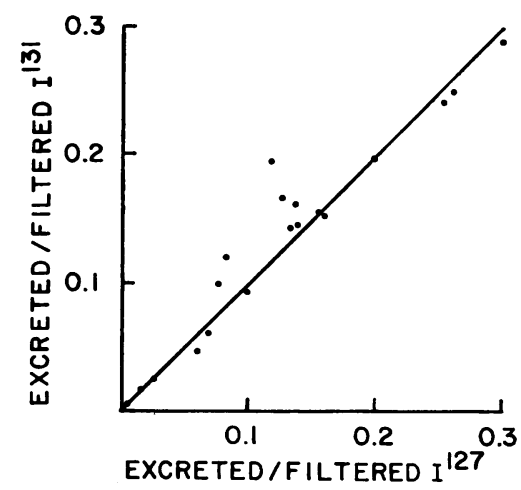

Fig. 1. Radioiodide clearance compared with STABLr IODIDE CLEARANCE IN FOUR EXPERIMENTS. ance. The results of these observations are summarized in Figure 4. Much lower iodide clearances were noted when the chloride excretion fraction was below 0.002 . In two experiments, iodide clearance became less than chloride clearance. In three osmotic diuresis experiments, urine-toplasma concentrations ratios for iodide of less than 0.01 were noted, the lowest value being 0.0015 . One such experiment is shown in Table V.' As indicated above, the true clearance ratios may have been even lower than those shown.

As Rector and Clapp (11) have pointed out, the lowest urine-to-plasma ratio consistent with passive back diffusion for a monovalent anion is approximately 0.01 . These results therefore establish the existence of active transport of the last traces of iodide, if active transport is defined as movement against an electrochemical gradient between urine and plasma. Since there is little or no correlation between chloride and iodide clearance shown in Figure 4, the active transport mechanism for iodide is evidently not the same as that described for chloride (11).

Variables affecting iodide-chloride discrimination. The results of the statistical analysis are summarized in Table VI. Twelve simultaneous 


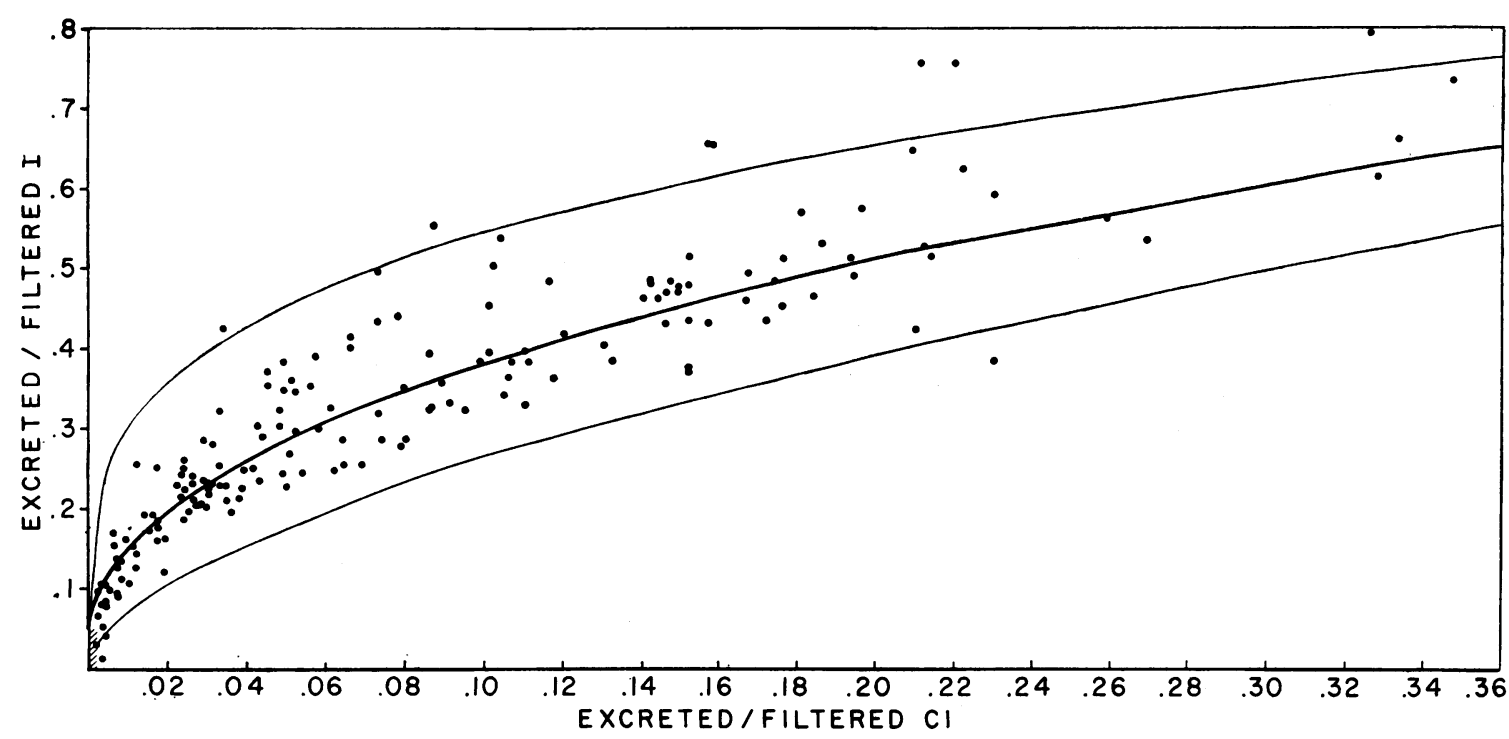

Fig. 2. EXCRETION FRACTION OF IODIDE IN RELATION TO THE SIMULTANEOUS EXCRETION FRACTION OF CHLORIDE IN 26 EXPERIMENTS. The three curves represent power functions, $y=x^{\mathbf{k}}$, with exponents $(\mathrm{k})$ of $0.28,0.42$, and 0.56 .

regressors were included; some of these were physiological variables that are always present; others were plasma concentrations or infused quantities of various solutes given to the animals.

The only one of these twelve variables that significantly affected iodide-chloride discrimination was urine flow. The regression coefficient for flow per unit glomerular filtration rate (GFR) was -0.81 . Since $\mathrm{k}$ is the exponent of a fraction, smaller values of $\mathrm{k}$ indicate higher clearances of iodide relative to chloride. Thus the effect of increasing flow at constant chloride clearance is to increase iodide clearance.

To obtain a more reliable estimate of the regression coefficient for flow, the statistical analysis was repeated excluding all the regressors except flow. The results indicate that $\mathrm{k}=0.47-0.7 \mathrm{~V} / \mathrm{GFR}$, where $\mathrm{V}$ is flow. The effect of flow is highly significant. This effect is not large, however. An increase in flow from zero to $5 \%$ of GFR, for ex-

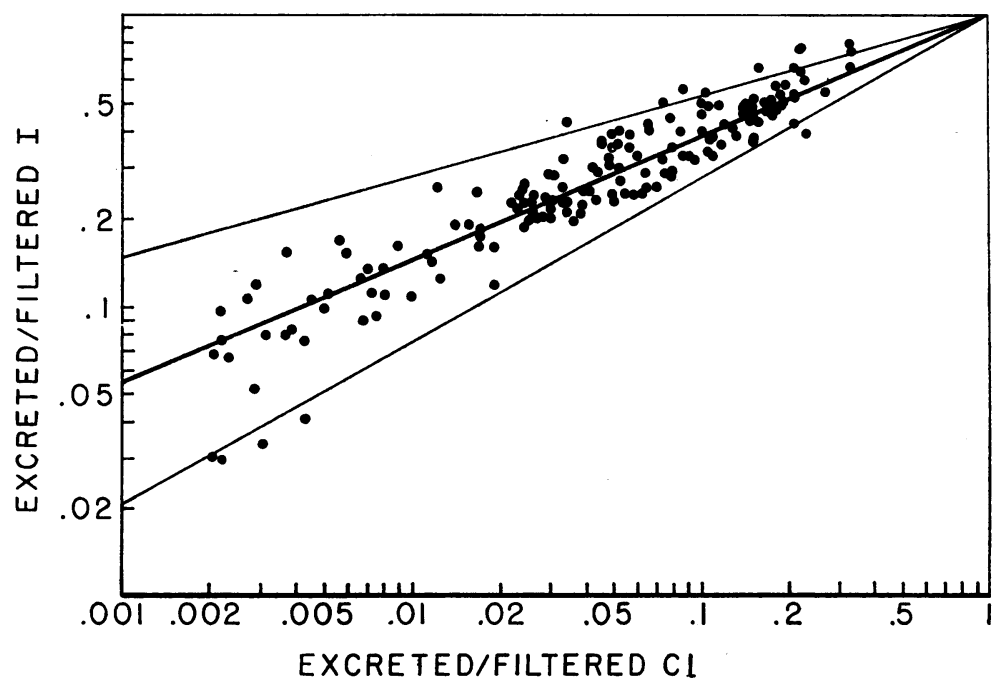

Fig. 3. Same data and curves as Figure 2 on logarithmic coordinates. 


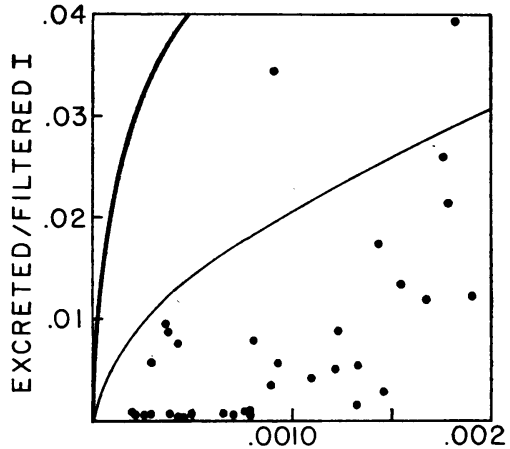

EXCRETED/FILTERED CL

Fig. 4. EXCRETION FRACTION OF IODIDE VERSUS THAT OF CHLORIDE AT EXTREMELY LOW CHLORIDE CLEARANCES. The heavy line represents $y=x^{0.18}$ and the light line $y=x^{0.50}$. Note that iodide clearance is even lower than chloride clearance in some instances.

ample, should increase the percentage excretion of filtered iodide only about $2 \%$, if chloride clearance remained constant.

Constancy of iodide-chloride discrimination. Table VII gives the average discrimination factor in each experiment and the estimates of period-toperiod and study-to-study variance. The latter is greater than the former. This finding results from the inclusion in the statistical analysis of the three experiments in which aberrant values were seen. The two high aberrant values occurred in dogs that had been studied previously on three or more occasions ( $6 \mathrm{G}$ and $6 \mathrm{~K}$ ). No explanation for this change in discrimination could be found, but it is conceivable that repeated doses of radioiodide or other side effects of the experimental procedure had led to some permanent physiological alterations. Unfortunately, it was not possible to perform further studies on these dogs. It can also be seen that study-to-study variation in individual dogs was comparable in magnitude to dog-to-dog variation. Thus the source of these changes in iodide-chloride discrimination does not lie entirely in individual differences between animals.

In individual experiments, iodide clearance can be predicted from chloride clearance as (excreted/ filtered chloride $)^{\mathrm{k}}$, where $\mathrm{k}=\alpha-0.698 \mathrm{~V} / \mathrm{GFR}$, and $\alpha$, the corrected mean (corrected for the regression on flow), is estimated in each study from the observed data by means of the statistical program. Thus at least one collection period must show close correspondence between observed and predicted iodide clearance. The range of iodide clearance in each experiment was considerable, however. Thus the close correspondence between observed iodide clearance and values predicted in this manner (Figure 5) indicates that this rela-

TABLE V

Iodide and chloride clearance during and following chloride depletion induced by osmotic diuresis*

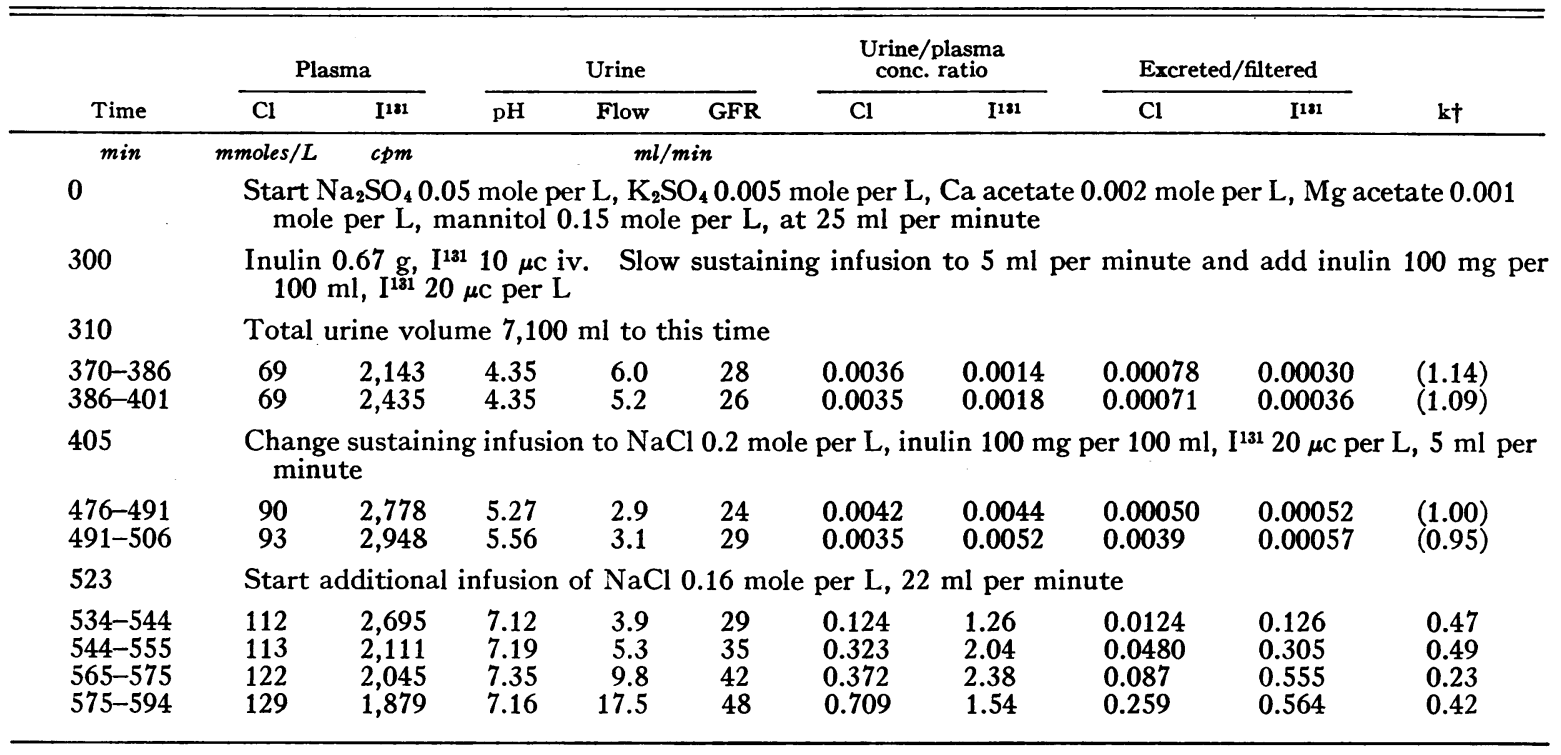

* Dog 6L, $13.4 \mathrm{~kg}$, regular diet.

$\dagger \mathrm{k}=\log ($ excreted/filtered I)/ $\log ($ excreted/filtered $\mathrm{Cl}$ ). Values in parentheses excluded from the statistical analysis because of low clearances. 
TABLE VI

Variables affecting iodide-chloride discrimination

\begin{tabular}{cr}
\hline \hline \multicolumn{1}{c}{ Regressor } & \multicolumn{1}{c}{ Coefficient $\pm \mathrm{SE}$} \\
\hline Physiological variables & \\
Urine flow, $\mathrm{ml} / \mathrm{ml} \mathrm{GFR}$ & $-0.806^{*} \pm 0.1360$ \\
Filtration rate, ml/min $/ \mathrm{kg}$ & $0.0060 \pm 0.0107$ \\
Plasma chloride, $m$ moles $/ L$ & $0.0010 \pm 0.0016$ \\
Infused substances & \\
Measured plasma levels, mmoles $/ L$ & \\
Iodide (17 periods) & $-0.0016 \pm 0.0020$ \\
Thiocyanate (76 periods) & $0.0115 \pm 0.0364$ \\
Estimated (no. periods infused) & $-0.0406 \pm 0.0328$ \\
Nitrate (68 periods) & $0.0888 \pm 0.0358$ \\
Perchlorate (52 periods) & $0.0174 \pm 0.0151$ \\
Sulfate (31 periods) & $-0.0386 \pm 0.0184$ \\
Aftereffect (16 periods) & $0.0035 \pm 0.0142$ \\
HCl (23 periods) & $0.0228 \pm 0.0384$ \\
Bicarbonate (12 periods) & $-0.0098 \pm 0.0654$ \\
Aftereffect (3 periods) &
\end{tabular}

* Value differs significantly from zero $(p<0.01)$.

tionship has high predictive value in individual experiments.

A comparison of iodide clearance with flow or with the clearance of sodium or potassium in these

TABLE VII

Mean iodide-chloride discrimination factors in individual experiments

\begin{tabular}{|c|c|c|c|}
\hline Dog & Experiment & Mean & $\begin{array}{c}\text { Corrected } \\
\text { mean* }^{*}\end{array}$ \\
\hline \multirow[t]{3}{*}{$6 \mathrm{C}$} & 1 & 0.368 & 0.388 \\
\hline & 2 & 0.407 & 0.472 \\
\hline & 3 & 0.449 & 0.526 \\
\hline $6 \mathrm{E}$ & 1 & 0.373 & 0.518 \\
\hline \multirow[t]{6}{*}{$6 \mathrm{~F}$} & 1 & 0.458 & 0.577 \\
\hline & 2 & 0.351 & 0.368 \\
\hline & 3 & 0.439 & 0.471 \\
\hline & 4 & 0.411 & 0.463 \\
\hline & 5 & 0.375 & 0.425 \\
\hline & 6 & 0.501 & 0.530 \\
\hline \multirow[t]{4}{*}{$6 \mathrm{G}$} & 1 & 0.417 & 0.449 \\
\hline & 2 & 0.401 & 0.408 \\
\hline & 3 & 0.425 & 0.445 \\
\hline & 4 & 0.662 & 0.674 \\
\hline \multirow{2}{*}{$6 \mathrm{H}$} & 1 & 0.424 & 0.466 \\
\hline & 2 & 0.421 & 0.432 \\
\hline 6I & 1 & 0.423 & 0.469 \\
\hline $6 \mathrm{~J}$ & 1 & 0.282 & 0.308 \\
\hline \multirow[t]{6}{*}{$6 \mathrm{~K}$} & 1 & 0.437 & 0.531 \\
\hline & 2 & 0.491 & 0.503 \\
\hline & 3 & 0.343 & 0.432 \\
\hline & 4 & 0.465 & 0.532 \\
\hline & 5 & 0.450 & 0.454 \\
\hline & 6 & 0.580 & 0.618 \\
\hline $6 \mathrm{~L}$ & 1 & 0.370 & 0.429 \\
\hline $6 \mathrm{P}$ & 1 & 0.471 & 0.485 \\
\hline $6 \mathrm{R}$ & 1 & 0.339 & 0.427 \\
\hline $6 \mathrm{~W}$ & 1 & 0.348 & 0.421 \\
\hline \multirow[t]{5}{*}{$6 \mathrm{Y}$} & 1 & 0.412 & 0.454 \\
\hline & Weighted means & 0.423 & 0.466 \\
\hline & Variance & & \\
\hline & Study to study & 0.0250 & \\
\hline & Period to period & 0.0198 & \\
\hline
\end{tabular}

* Corrected for the regression on flow.

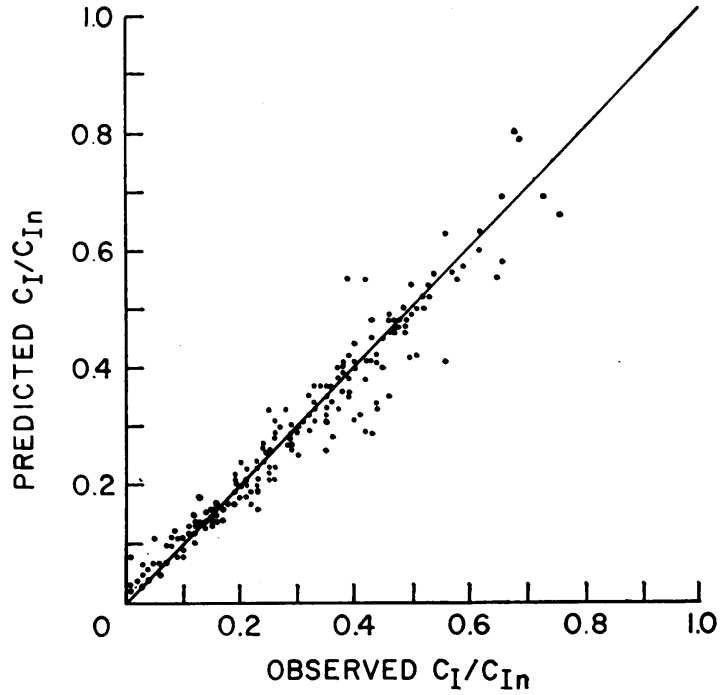

Fig. 5. Predicted versus observed iodide clearance $\left(C_{1}\right)$. The predicted value was obtained as (excreted/filtered chloride) ${ }^{k}$, where $\mathrm{k}=\alpha-0.698$ flow/GFR, and $\alpha$ is an assigned value in each of 29 experiments. $C_{I n}=$ inulin clearance.

same experiments indicated that none of these relationships approached the degree of uniformity seen in the relationship with chloride clearance. For example, sulfate infusion was often accompanied by high flow and high cation clearances but extremely low clearances of iodide and chloride.

\section{Discussion}

The mechanism of renal excretion of iodide and its relationship to that of chloride has been a subject of some controversy. A reduction in iodide excretion in dogs depleted of chloride was noted in 1911 (12). A preliminary report by Riggs (13) confirmed this conclusion in dogs, but such was said not to be the case in man (14). Bricker and Hlad (15) examined radioiodide and inulin clearances in human subjects under a variety of circumstances. They concluded that iodide was filtered and reabsorbed, but that its tubular transport was not predictably related to that of any other ion, including chloride. However, some correlation between iodide and chloride clearance can be seen in their reported data, which have been estimated from their graphs and replotted in Figure 6 on logarithmic coordinates. The average discrimination factor appears to be approximately 0.25 .

Giebisch, MacLeod, and Kavaler (8) found that 


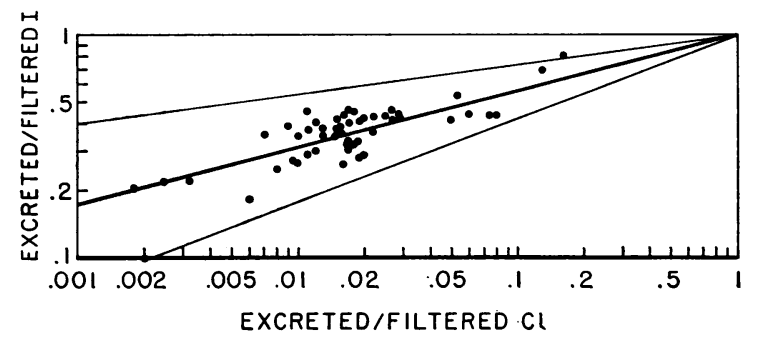

Fig. 6. IODIDE CLEARANCE versus ChLORIDE CLEARANCE in MAN, ReCAlculated From Bricker aNd HLAd (15). Three observations during mercurial diuresis omitted.

radioiodide clearance in dogs was increased by mannitol, $\mathrm{NaCl}, \mathrm{NaBr}$, or $\mathrm{NaHCO}_{3}$ diuresis. Water diuresis had little effect. Although these data might suggest an interrelationship between chloride and iodide clearance, chloride was not measured. Halmi and associates (16) administered $\mathrm{NaCl}, \mathrm{NaClO}_{4}, \mathrm{NaI}, \mathrm{NaBr}, \mathrm{NaHCO}_{3}$, choline iodide, or $\mathrm{Na}_{2} \mathrm{~S}_{2} \mathrm{O}_{3}$ to rats given $\mathrm{I}^{181}$ subcutaneously. All of these salts except $\mathrm{Na}_{2} \mathrm{~S}_{2} \mathrm{O}_{3}$ increased $\mathrm{I}^{131}$ excretion, urine flow, and possibly chloride excretion. Filtration rates were not measured. They concluded that iodide reabsorption is both passive and active, being capable of saturation by iodide and inhibition by other anions. Stop-flow analysis indicates that iodide is reabsorbed in the same regions as chloride, although less completely (17). Injected radioiodide gains access to the tubular fluid from the peritubular capillaries less readily than does bromide (18). Cassano, Baschieri, and Andreani (19), studying normal and goitrous subjects, found some correlation between iodide and chloride clearance, but evidently not a clear-cut one. They report that iodide clearance exceeds creatinine clearance in a small percentage of individuals, and is regularly reduced by probenecid.

A general concept of competitive reabsorption of small anions was put forward by Kruhoffer (20), based upon a review of the literature. Later Saugman (7), working in the same laboratory, measured simultaneous clearances of creatinine, chloride, and either iodide, nitrate, or thiocyanate in rabbits, dogs, and man. $\mathrm{He}$ concluded that "[small] anion reabsorption appears to take place as a mutual competition in which the physicalchemical properties of the anions decide the mutual rate of reabsorption." This work, published only as a thesis in Danish, is not widely known.
Saugman reported 60 simultaneous observations of iodide and chloride excretion fractions in dogs, but did not plot one against the other. The discrimination factor calculated from his data (neglecting flow or any other regressors) is $0.398 \pm$ 0.058 (SD), a value consistent with the present data.

Thus, wherever definite data are available, the power function relationship between iodide and chloride clearance provides an adequate description of the results. It appears that iodide clearance relative to chloride clearance is greater in man than in dogs, and the possibility of iodide secretion in this species has not been eliminated.

These findings provide support for the report of Isler (21) that thyroid function may be correlated with salt intake, and emphasize the importance of taking salt excretion into account in evaluating the thyroid uptake or urinary excretion of administered doses of radioiodide. Within the usual range of variation in chloride excretion, this effect may be small, but during severe salt restriction (or retention) with excreted/filtered chloride ratios less than 0.002 , iodide may virtually disappear from the urine, at least in the dog (Figure 4).

A relationship between iodide transport in the thyroid and in the kidney is not supported by these studies, at least as far as the major portion of iodide reabsorption is concerned. Neither thiocyanate nor perchlorate administration affected iodide-chloride discrimination, nor did iodide loading. Thus the reported effects of these agents on iodide clearance $(16,22)$ may be a result of effects on fluid reabsorption or electrical potential, thereby increasing the clearances of all monovalent anions, rather than an indication of specific inhibition of iodide transport.

On the other hand, the mechanism responsible for the active reabsorption of the last traces of iodide, which becomes apparent only at very low chloride clearances, may well exhibit some of the properties of the thyroidal transport system. We have recently reported (5) that thiocyanate clearance relative to chloride clearance is increased during infusion of perchlorate or iodide, suggesting that a distal active transport mechanism for thiocyanate may play a significant role in its reabsorption. However, in one of the four experiments in the present series in which the urine-to-plasma concentration ratio for iodide was less than 0.01 , 
indicating active transport, thiocyanate was present at a plasma concentration of 3 mmoles per $\mathrm{L}$. Further study of iodide clearance at low chloride clearances in the presence of thiocyanate or perchlorate would be of interest.

The usual manner in which renal discrimination between two solutes is expressed is as the ratio of their clearances. This might be termed urinary discrimination. If tubular discrimination, as defined herein, remains constant, urinary discrimination may nevertheless vary widely. The relationship should be : iodide clearance/chloride clearance $=(\text { excreted } / \text { filtered chloride })^{\mathbf{k}-1}$ as can be seen by rearranging the simple power function. A graph of urinary discrimination against chloride excretion fraction should therefore be a straight line on logarithmic coordinates. Figure 7 illustrates this relationship for the same 26 experiments. Urinary discrimination decreased from 40 to 2 with increasing chloruresis.

The principle difference between the approach employed here and previous studies of iodide clearance lies in the use of the simultaneous chloride clearance as a referent. This referent provides an index of the magnitude of a parameter of renal function that expresses the momentary balance between the filtration and reabsorption of monovalent anions. An increase in the total filtered load of monovalent anions or an increase in the relative proportion of less permeant anions tends to increase the excretion fraction of all. A decrease in

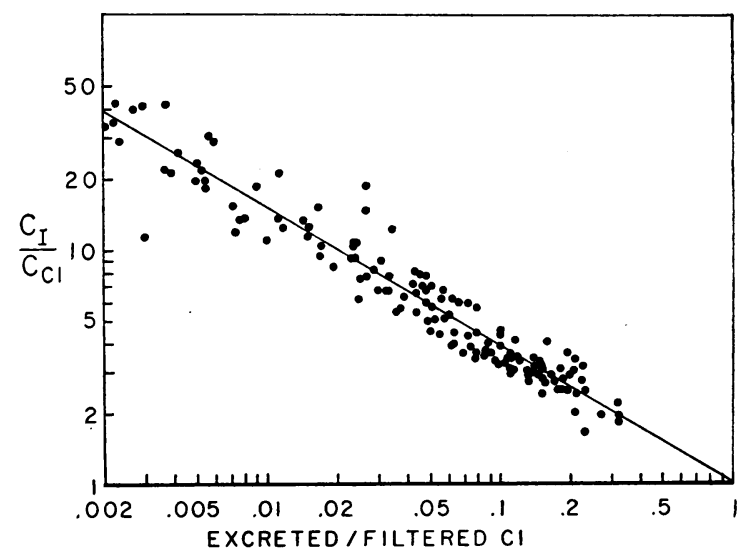

Fig. 7. The ratio of iodide to chloride clearance AS A FUNCTION OF THE EXCRETION FRACTION OF CHLORIDE. The relationship is linear on logarithmic coordinates, and the ratio approaches a limiting value of unity. the rate of tubular reabsorption of water or in the transtubular electrical potential gradient also tends to increase the excretion fractions of all. Although chloride has no more primary role than any other anion in this scheme, it is the most conveniently measured. When iodide or bromide (4) clearance is viewed in the light of this parameter, many of the agents previously found to augment these clearances are seen to have nonspecific effects on monovalent anions in general, probably by means of one of the above mechanisms.

Bicarbonate, like sulfate or phosphate, cannot be considered a passively reabsorbed anion, since its removal is clearly limited by a maximal rate. These anions removed by pump mechanisms therefore show no consistent relationship to the simultaneous clearances of halides.

\section{Summary}

Simultaneous clearances of inulin, chloride, and radioiodide, during constant infusion of the latter, were measured in dogs salt depleted or infused with solutions of glucose, mannitol, $\mathrm{NaCl}, \mathrm{Na}_{2} \mathrm{SO}_{4}$, $\mathrm{NaHCO}_{3}, \mathrm{HCl}, \mathrm{NaI}, \mathrm{NaBr}, \mathrm{NaSCN}, \mathrm{NaNO}_{3}$, $\mathrm{NaClO}_{4}$, or combinations of these. The data were examined to determine whether they were consistent with the possibility that iodide and chloride are passively and coextensively reabsorbed, with the ratio of the tubular permeabilities to the two ions unchanging along the length of the tubule. If this were the case, log (excreted/filtered I)/log (excreted/filtered $\mathrm{Cl}$ ) $=\mathrm{k}$ should be nearly constant, at least in individual experiments. The calculated discrimination factor $\mathrm{k}$ was independent of plasma chloride or iodide levels, filtration rate, or the administration of these infusions. Increasing flow decreased $\mathrm{k}$ indicating the iodide clearance varies slightly with flow independently of chloride clearance. For all of the experiments, $\mathrm{k}=0.468$ -0.7 (flow/glomerular filtration rate). In individual experiments, values of iodide clearance predicted in this manner from chloride clearance and urine flow were closely correlated with observed iodide clearance. These results are thus consistent with the hypothesis. However, at very low excretion fractions of chloride $(<0.002)$, active transport of iodide became apparent, and iodide reabsorption in some instances was more nearly complete than chloride reabsorption. 


\section{Acknowledgments}

We are greatly indebted to Sylvia Butler, Shirley Washington, and Virginia Alexander for technical assistance, and to Emily Kirstein and John C. Finck for assistance with the programming.

\section{References}

1. Walser, M., and W. J. Rahill. Renal tubular reabsorption of halides. J. clin. Invest. 1963, 42, 990.

2. Walser, M., and W. J. Rahill. Evidence for a single transport system for monovalent anions. Physiologist 1963, 6, 292.

3. Walser, M. Some mathematical aspects of the renal tubular reabsorption of water and solutes. J. theor. Biol., submitted for publication.

4. Walser, M., and W. J. Rahill. Renal tubular reabsorption of bromide as compared with chloride. Submitted for publication.

5. Walser, M., and W. J. Rahill. Nitrate, thiocyanate and perchlorate clearance in relation to chloride clearance. Amer. J. Physiol., in press.

6. Toribara, T. Y., A. R. Terepka, and P. A. Dewey. The ultrafiltrable calcium of human serum. I. U1trafiltration methods and normal values. J. clin. Invest. 1957, 36, 738.

7. Saugman, B. The excretion of easily diffusible anions in mammals. Thesis, Univ. of Copenhagen, 1957.

8. Giebisch, G., M. B. MacLeod, and F. Kavaler. Renal excretion of radioiodide in the dog. Amer. J. Physiol. 1956, 187, 529.

9. George, E. P., and W. Sollich. The adsorption of I-131 iodide ions on plasma proteins. Aust. J. exp. Biol. med. Sci. 1959, 37, 289.

10. Duncan, D. B., and M. Walser. Multiple regression in a 'split-plot' context combining within- and between-plot information. Biometrics, in press.
11. Rector, F. C., Jr., and J. R. Clapp. Evidence for active chloride reabsorption in the distal renal tubule of the rat. J. clin. Invest. 1962, 41, 101.

12. Sarvonat, F., and R. Crémier. La fixation du brome et de l'iode par les organismes déchlorurés. J. Physiol. Path. gén. 1911, 13, 589.

13. Riggs, D. S. Renal clearance of iodide in the dog. Fed. Proc. 1949, 8, 328.

14. Riggs, D. S. Quantitative aspects of iodine metabolism in man. Pharmacol. Rev. 1952, 4, 284.

15. Bricker, N. S., and C. J. Hlad, Jr. Observations on the mechanism of the renal clearance of $\mathrm{I}^{121}$. J. clin. Invest. 1955, 34, 1057.

16. Halmi, N. S., L. T. King, R. R. Widner, A. C. Hass, and R. G. Stuelke. Renal excretion of radioiodide in rats. Amer. J. Physiol. 1958, 193, 379.

17. Williamson, H. E., J. R. Scranton, F. N. Marshall, and N. S. Halmi. Stop flow analysis of renal tubular site of reabsorption of radioiodide in dogs. Proc. Soc. exp. Biol. (N. Y.) 1962, 109, 23.

18. Kiil, F., and K. Aukland. Renal tubular permeability to radioactive sodium, bromide, and iodide isotopes. Scand. J. clin. Lab. Invest. 1962, 14, 124.

19. Cassano, C., L. Baschieri, and D. Andreani. Etude de 48 cas de goitre simple avec élèvation de la clearance rénale de l'iode in Advances in Thyroid Research, R. Pitt-Rivers, Ed. New York, Pergamon, 1961, p. 307.

20. Kruhoffer, P. Studies on water-electrolyte excretion and glomerular activity in the mammalian kidney. Copenhagen, Rosenkilde and Bagger, 1960.

21. Isler, $H$. Effect of sodium chloride on the gland and on iodide metabolism. Amer. J. Cardiol. 1961, 8, 688.

22. Ermans, A. M., and F. Goossens. Influence du perchlorate et du méthimazol sur l'excrétion urinaire de l'iode chez l'homme. Arch. int. Pharmacodyn. 1961, 132, 487. 